\title{
Yerel Cin Mısırı Genotiplerinin Kahramanmaraş Koşullarında Tarımsal Özelliklerinin Araştırılması
}

\author{
Leyla İDİKUT, Gülay ZULKADİR, Cengiz YÜRÜRDURMAZ, Mustafa ÇÖLKESEN \\ KSÜ, Ziraat Fakültesi, Tarla Bitkileri Bölümü, Kahramanmaraş
}

\author{
Geliş (Received): 28.01.2015
}

\author{
Kabul (Accepted): 08.07.2015
}

\begin{abstract}
ÖZET: Bu araştırma, ülkenin farklı yerlerinden toplanan 10 yerel popülasyon ile 2 yerel çeşit ve birde kompozit olmak üzere toplam 13 cin mısırı genotipi kullanılarak, Kahramanmaraş koşullarında iki (2012 ve 2013) yıl süreyle yürütülmüştür. Deneme tesadüf blokları deneme desenine göre dört tekerrürlü yürütülmüştür. Araştırmada cin mısırının tepe püskül çıkış süresi, koçan püskülü çıkış süresi, ilk koçan yüksekliği, bitki boyu, koçan uzunluğu, koçan çapı, koçanda sıra sayısı, koçan sırasına tane sayısı, bitki başına koçan sayısı, tane oranı, dekara verim, patlama hacmi ve patlamamış tane oranı incelenmiştir. Araştırmanın iki yıllık ortalama sonuçlarına göre incelenen özelliklerden yalnız bitki başına koçan sayısı yönünden genotipler arasındaki farklılığın önemsiz diğer özellikler arasındaki farklılıkların ise istatistiki olarak önemli olduğu belirlenmiştir. Denemenin iki yıllık ortalama sonuçlarına göre cin mısırı popülasyonunda tepe püskülü çıkış süresi 54-66 gün, bitki boyu $134-181 \mathrm{~cm}$, patlama hacmi 10-22 $\mathrm{m}^{3} \mathrm{~g}^{-1}$, patlamamış tane oranı $\% 8-24$, tane verim değerleri $369-498 \mathrm{~kg} \mathrm{da}^{-1}$ olarak kaydedilmiştir. Tane verimi, erkencilik ve patlama hacmi dikkate alındığında Kadirli cin, Samsun cin, Kompozit cin ve Edirne beyaz cin genotiplerinin bölge için önerilebileceği belirlenmiştir.
\end{abstract}

Anahtar kelimeler: Cin misirı, yerel genotipler, tane verimi

\section{Investigation of Agricultural Characteristics of Local Popcorn Genotypes in Kahramanmaras Conditions}

ABSTRACT: This study with total 13 genotypes that is two local varieties and one composite with 10 popcorn population collected from different parts of the country was conducted in Kahramanmaraş conditions in 2012 and 2013 years. The experiment was conducted in randomized block desing with four replications. The ear tassel-out time, ear silk-out time, first ear height, plant height, ear lenght, ear diameter, number of grains on row per ear, row number per ear, ear number per plant, percentage of grain ratio, grain yield, popping volume and percentage of unpopped kernels of popcorn were investigated. According to the results of the averageof two years, the except for ear number per plant from examination characteristics, the difference among the other characteristic in terms of genotypes were determined significant as statistical. Considering the average of the two years, the ear tassel-out time, plant height, popping volume and percentage of unpopped kernels and grain yield of popcorn were determined as 54-66 days, $134-181 \mathrm{~cm}, 10-22 \mathrm{~m}^{3} \mathrm{~g}^{-1}, \% 8-24,369-498 \mathrm{~kg} \mathrm{da}^{-1}$ respectively. Considering the grain yield, earliness and the poppin volume Kadirli pop, Samsun pop, Composite pop ve Edirne white pop genotypes can be recommended for the region.

Key Words: Pop corn, local genotypes, grain yield

\section{GíRiş}

Dünya üzerinde yaşayan insanlar, sürekli mevcut yaşam koşullarını daha iyiye götürmek için arayış içinde olmuşlardır. $\mathrm{Bu}$ arayış çevrenin genişletilmesiyle sürdürülmüştür. Çevrenin genişletilmesi küreselleşme olgusunu ortaya koymuştur. Küreselleşme her alanda etkili olurken en büyük baskıyı tarım ürünlerinde göstermiştir. Verimlilik ve kar, tarım ürünlerinin ticaretinin serbest olmasını ve bir ürünün çok farklı bölgelere yayılmasına sebep olmuştur. Bir ürünün farklı bölgelere yayılması firsat yarattığ 1 kadar riskte oluşturmaktadır.

Tarımı en fazla yapılan ürün grubu tahıldır. Tahıl ürünlerinden buğday ekim alanı olarak birinci sırada yer almaktadır. Ülkemizde en fazla ekim alanı 2014 yılı için buğday (79.192.084 da), arpa (27.872.973 da) ve üçüncü sırada 6.586 .450 dekar ekim alanı ile misır bitkisi gelmektedir (Anonim, 2015). Misır bitkisinin kısa sürede yetişmesi ve tek evcikli olması genetik çalışmaları kolaylaştırmıştır. Tane yapılarına göre mısırın at dişi, sert mısır, şeker mısırı ve cin mısır formları yaygın olarak kullanılmaktadır. Misır bitkisi hem dünyada, hem de ülkemizde yirmi birinci yüz yılda stratejik, önemli bir ürün haline gelmiştir. Bu nedenle mısırın doğal yapısı üzerinde çok fazla değişim yapılmıştır. Her bölgeye ve koşullara uygun ticari hibrit mısır üretimi yerel çeşitlerin yok oluşunu hızlandırmıştır.

Hibrid çeşitlerin yaygınlaştırılması, çok fazla girdi kullanılması ve tarımda artan ticarileştirme oranı yerel bitki türlerinin üretim alanını daraltmıştır. Yüksek verimli hibrid çeşitler baskın olsa da, yerel çeşitler bazı bölgelerde hala ekilmektedir. Yerel mısır çeşitlerimiz mevcut bulunduğu çevrede doğal seleksiyonunu tamamlayarak, genellikle olumsuz koşullarda ürün vermeyi başarmıştır. Kendi içlerinde bile yerel çeşitlerin farklı genetik varyasyonlara sahip olma özellikleri, birbirlerinin eksikliklerini tamamlayarak ticari çeşitlerine göre bazı özellikler bakımından daha üstün olabilmektedirler (Allard ve Bradshaw, 1964). Bu nedenle yerel çeşitlerimizin gen kaynakları korunarak, 
daha sonraki nesillerin kullanabilmesine fayda sağlayacak önemli çalışmalar yapılmalıdır.

Patlamış mısır dünya üzerinde en yaygın tüketilen çerez gıdalardan biridir. Ülkemizde cin mısırı çerezlik olarak kullanıldığından, ülke genelinde küçük alanlarda ekilmektedir. İçerdiği vitamin ve mineraller nedeniyle beslenme açısından tercih edilen bir gıda maddesidir. Tok tutucu ve mide asidini emici özelliğiyle de iyi bir diyet ürünüdür (Ülger ve ark. 1998). Son yıllarda, birim fiyatının yüksek olması nedeniyle üretim alanlarında artma olmaktadır. Özellikle çocukların severek yediği patlamış mısırların GDO grubunda yer alması ve tüketicilerdeki metabolizma değişikleri gibi insan sağlığına olumsuz etkileri olmasının muhtemel olduğu bildirilmektedir (Saltık, 2010).

$\mathrm{Bu}$ çalışmamızda bitki ıslahı ve genetik çalışmalar için önemli olan, genetiği ile oynanmamış, ülkenin değişik yerlerinden temin edilmiş 13 cin misır genotipinin bazı özellikleri belirlenmeye çalışılmıștır.

\section{MATERYAL ve METOT}

\section{Materyal}

Araştırma 2012-2013 yıllarında birinci ürün yetiştirme sezonunda Kahramanmaraş koşullarında iki süreyle 10 adet yerel popülasyon, 2 çeşit ve birde kompozit materyal olmak üzere toplam 13 cin misırı materyali kullanılarak yürütülmüştür. Çalışmada kullanılan cin misırı materyalleri Ant cin ve Nemin cin Batı Akdeniz Tarımsal Araştırma Enstitüsü Müdürlügüünden, Komposit cin Sakarya Mısır Araştırma İstasyonu Müdürlüğünden temin edilmiştir. Diğer on yerel (Çanakkale sarı patlak, Çanakkale kırmızı patlak, Çanakkale beyaz patlak, Samsun cin ve Samsun beyaz cin, Kadirli cin, Balıkesir cin ve Balıkesir beyaz cin, Edirne beyaz cin, Sakarya-Hanköyü) popülasyonda temin edildiği yöre ve tane rengine göre tarafımızdan isimlendirilmiştir.

\section{Yöntem}

Deneme arazisinde misır ekiminden önce pamuk tarımı yapılmıştır. İkinci yılda aynı deneme yeri kullanılmıștır. Her iki yılda da sonbaharda ürün tarlayı boşaltınca derin sürüm yapılarak bırakılmıştır. Kışın deneme alanı boş kalmıştır. Mart ayında toprak hazırlığ yapılmıştır. Toprak diskaro ve rotillerle işlenerek, üzerinden tapan çekilerek toprak ekime hazır hale getirilmiştir. Ekim tavlı toprağa birinci yıl 25 Nisan
2012, ikinci yıl 4 Nisan 2013 tarihinde el ile yapılmıştır. Birinci yıl Nisan ayında yağışların fazla olması ve toprak işlenememesi nedeniyle ekim erken yapılamamıştır. Araştırma tesadüf blokları deneme desenine göre 4 tekerrürlü olarak kurulmuştur. Ekimde her parsel $5 \mathrm{~m}$ uzunluğunda 4 sıra olacak şekilde $70 \mathrm{~cm}$ sira arası ve $20 \mathrm{~cm}$ sira üzeri mesafesinde oluşturulmuştur. Her parsel arasında bir sırada boş ve her blok arasında $2.5 \mathrm{~m}$ boşluk bırakılmıştır. İki el çapası iki kez traktör çapası yapılmıştır. Ekim sırasında toprağa saf $10 \mathrm{~kg} \mathrm{da}^{-1}$ azot ve 10 fosfor gübresi toprağa karıștırılmıştır. Üst gübre olarak $17 \mathrm{~kg} \mathrm{da}^{-1}$ net azot (\% 33 Nitrat) bitki $50 \mathrm{~cm}$ iken verilmiştir. Birinci yıl hava sıcaklığına, toprak ve bitki durumuna göre $9 \mathrm{kez}$, ikinci ise 8 kez karık usulü sulama yapılmıştır. Her iki yılda da hasat Eylül ayının ilk haftası yapılmıştır.

Cin mısırının tepe püskül çıkış süresi (gün), koçan püskülü çıkış süresi (gün), ilk koçan yüksekliği $(\mathrm{cm})$, bitki boyu $(\mathrm{cm})$, koçan uzunluğu $(\mathrm{cm})$, koçan çapı $(\mathrm{cm})$, koçanda sıra sayısı (adet), koçan sırasında tane sayısı (adet), bitki başına koçan sayısı (adet), tane oranı (\%), dekara verim $\left(\mathrm{kg} \mathrm{da}^{-1}\right)$, patlama hacmi $\left(\mathrm{m}^{3} \mathrm{~g}^{-1}\right)$ ve patlama oranı (\%) incelenmiștir. Cesurer (1995)'de ve Özkan (2011)'da uygulanan yöntemlerden yararlanılmıştır.

Deneme yerinin toprak yapısı KSÜ Ziraat Fakültesi Toprak ve Bitki Besleme Bölümü laboratuvarında yapılan analiz sonuçlarına göre; killi-tınlı (\% 62.5), tuzsuz (\% 0.12), fazla kireçli (\% 22.8), kuvvetli alkali $(\mathrm{pH}=8.1)$, organik madde $(\% 1.46)$ az, fosfor $(4.46$ $\mathrm{mg} / \mathrm{kg})$ ve potasyum $(66.85 \mathrm{mg} / \mathrm{kg})$ az olarak tespit edilmiştir. Yerel cin mısırı genotiplerinin yetiştirildiği yıllara ve uzun yıllara ait iklim değerleri Çizelge 1'de verilmiştir (Anonim, 2014).

Çizelge 1'den Kahramanmaraş ilinde mısırın çiçeklenme döneminde nispi nem \% 50'nin altına, maksimum sıcaklığın $40{ }^{\circ} \mathrm{C}$ üstünde ve yağışın hiç yok denecek kadar az olduğu görülmektedir. $\mathrm{Bu}$ nedenden mısır tarımında sık sulamaya ihtiyaç duyulmaktadır.

Araştırma sonunda elde edilen veriler ANOVA yöntemine göre SAS istatistik programı kullanılarak analiz edilmiştir. İstatistiki olarak önemli farklılık gösteren özelliklerin ortalamaları Duncan çoklu karşılaştırma testine göre gruplandırılmıştır. Araştırmada incelenen özelliklerin bulguları iki yıllın ortalamasına göre verilmiştir. 
Çizelge 1. Araştırmanın yapıldığı yıllara ve uzun yıllara ait Kahramanmaraş ilinin bazı iklim değerleri

\begin{tabular}{|c|c|c|c|c|c|c|}
\hline Aylar & Yillar & $\begin{array}{c}\text { Maksimum } \\
\text { sicaklik }\left({ }^{\circ} \mathrm{C}\right)\end{array}$ & $\begin{array}{c}\text { Minimum } \\
\text { sicaklık }\left({ }^{\circ} \mathrm{C}\right)\end{array}$ & $\begin{array}{c}\text { Ortalama } \\
\text { sicaklık }\left({ }^{\circ} \mathrm{C}\right)\end{array}$ & $\begin{array}{l}\text { Ortalama nispi } \\
\text { nem }(\%)\end{array}$ & $\begin{array}{c}\text { Toplam } \\
\text { yağış }(\mathrm{mm})\end{array}$ \\
\hline \multirow{3}{*}{ Nisan } & 2012 & 31.0 & 7.9 & 17.7 & 49.3 & 59.6 \\
\hline & 2013 & 33.1 & 8.4 & 17.2 & 51.9 & 65.9 \\
\hline & Uzun yıllar & 36.0 & -1.8 & 15.4 & 58.1 & 74.7 \\
\hline \multirow{3}{*}{ Mayıs } & 2012 & 30.5 & 12.3 & 19.9 & 55.8 & 41.3 \\
\hline & 2013 & 34.0 & 12.1 & 22.2 & 51.0 & 76.5 \\
\hline & Uzun yıllar & 38.0 & 5.0 & 20.3 & 54.8 & 40.4 \\
\hline \multirow{3}{*}{ Haziran } & 2012 & 41.1 & 15.2 & 27.9 & 33.4 & 13.0 \\
\hline & 2013 & 39.1 & 14.8 & 25.6 & 41.5 & 16.3 \\
\hline & Uzun yıllar & 42.0 & 10.3 & 25.2 & 49.4 & 6.7 \\
\hline \multirow{3}{*}{ Temmuz } & 2012 & 43.4 & 19.0 & 30.5 & 33.9 & 1.7 \\
\hline & 2013 & 39.3 & 21.0 & 28.8 & 35.4 & 0.0 \\
\hline & Uzun yıllar & 45.2 & 15.6 & 28.3 & 51.1 & 1.1 \\
\hline \multirow{3}{*}{ Ağustos } & 2012 & 40.9 & 21.3 & 29.9 & 37.9 & 0.0 \\
\hline & 2013 & 40.4 & 21.0 & 29.3 & 36.9 & 0.0 \\
\hline & Uzun yıllar & 44.4 & 15.7 & 28.4 & 52.5 & 0.8 \\
\hline \multirow{3}{*}{ Eylül } & 2012 & 38.9 & 16.9 & 27.0 & 38.8 & 0.0 \\
\hline & 2013 & 37.8 & 13.8 & 24.8 & 40.0 & 37.5 \\
\hline & Uzun yıllar & 41.3 & 8.6 & 25.1 & 49.6 & 7.2 \\
\hline
\end{tabular}

\section{BULGULAR ve TARTIŞMA}

Tepe Püskülü Çıkış Süresi (gün)

İki yıllık ortalama sonuçlara göre tepe püskülü çıkış süresi yönünden genotipler arasında istatistiki olarak önemli farklılıklar kaydedilmiştir. En erken tepe püskülü çıkışı 54.75 gün ile Edirne beyaz cin mısırında, 58.63 gün ile Çanakkale kırmızı patlak ikinci sırada erkencilikle diğerlerinden önemli farklılık göstermiştir. En geç ise 66.50 gün ile Çanakkale sarı patlak mısırda gerçekleşmiş, onu 64.50 gün ile ikinci sırada Samsun beyaz cin izleyerek bir geçiş grubunu oluşturmuştur. Ant cin, Nermin cin, Çanakkale beyaz patlak, Samsun cin, Kadirli cin, Balıkesir beyaz cin, ve SakaryaHanköyü cin genotipleri kendi aralarında istatistiki olarak fark oluşturmayıp aynı grupta yer almışlardır. Komposit cin ve Balıkesir cin genotipleride kendi aralarında aynı grubu oluşturmuşlardır (Çizelge 2).

Tekkanat ve Soylu (2005) 12 cin misırı genotipiyle yapmış oldukları araştırmada çiçeklenme süresinin 6973 gün arasında değiştiğini belirtmişlerdir. Öz ve Kapar (2011) 22 adet cin misırı hibrid genotiple yapmış oldukları çalışmada çiçeklenme gün sayısı 67-74 gün arasında değiştiği ve aralarında önemli farklılıklar oluşturduğunu kaydetmişlerdir. Bulut ve ark. (2008), silajlık mısırda tepe püskülü çıkış süresinin 79.8 ve 82.4 gün olarak tespit etmişlerdir. Tepe püskülü çıkış sürelerinin daha önce yapılan çalışmalardan farklı olması, kullandığımı genotiplerin yerel olması ve bölge koşularının farklı olmasından kaynaklanmaktadır. Rattalino Edreira ve Otegui (2012) sıcaklık gibi çevresel faktörlerin genotipler arasında çiçeklenme yönünden varyasyon oluşturduğunu belirtmiştir. Gökmen ve ark
(2001) ekim sıklığı ve azot dozunun artmasıyla tepe püskülü çıkış süresinin azaldığını kaydetmişlerdir. İdikut ve Kara (2011) tepe püskülü çıkış süresi yıllara göre önemli farklılık oluşturduğu ve tepe püskülünün genotip, iklim ve çevresel faktörlerden etkilendiğini açıklamıştır.

\section{Koçan Püskülü Çıkış Süresi (gün)}

Koçan püskülü çıkış süresi yönünden genotipler arasında istatistiki olarak önemli farkl1l1klar kaydedilmiştir. En erken koçan püskülü çıkışı 58.75 gün ile Edirne beyaz cin mısırında, Çanakkale kırmızı patlak 64.12 gün ile ikinci sırada erkencilikle diğerlerinden önemli farklılık göstermiştir. Koçan püskülü çıkışı en geç ise 70.12 gün ile Çanakkale sarı patlak ve Samsun beyaz cin genotipinde gerçekleştiği ve diğerlerinden önemli derecede farklılık oluşturduğu tespit edilmiştir. Ant cin, Kompozit cin, Samsun cin, Kadirli cin, Balıkesir cin ve Sakarya-Hanköyü cin genotipleri koçan püskülü çıkış süresi yönünden kendi aralarında istatistiki olarak fark oluşturmayıp aynı grupta ve geçiş grubunda yer almışlardır. Çanakkale Beyaz patlak ve Balıkesir beyaz cin genotipleride kendi aralarında aynı grup ve diğer bir geçiş grubunu oluşturmuşlardır. Nermin cin çeşidi de diğer bir geçiş grubunda yer almıştır (Çizelge 2).

Bulut ve ark. (2008) silajlık mısırda koçan püskülü çıkarma süresi 84.7 ve 86.3 gün, olarak kaydetmişlerdir. Rattalino Edreira ve Otegui (2012) sıcaklık gibi çevresel faktörlerin genotipler arasında çiçeklenme yönünden varyasyon oluşturduğunu belirtmiş̧tir. Tsimba ve ark. (2013b) değişen çevre koşulları altında tepe püskülü 
çıkış süresinin koçan püskülü çıkış süresine göre daha

stabil olduğunu belirtmişlerdir.

Çizelge 2. Yerel cin mısırı genotiplerinin incelenen bazı özelliklerinden elde edilen iki yıllık ortalama değerleri

\begin{tabular}{|l|l|l|l|l|l|l|}
\hline \multicolumn{1}{|c|}{ Genotip } & $\begin{array}{c}\text { Tepe Püskülü } \\
\text { Ç1k1ş Süresi } \\
(\text { gün})\end{array}$ & $\begin{array}{c}\text { Koçan Püskülü } \\
\text { Ç1k1ş Süresi } \\
(\text { gün })\end{array}$ & $\begin{array}{c}\text { İlk Koçan } \\
\text { Yüksekliği } \\
(\mathrm{cm})\end{array}$ & \multicolumn{1}{|c|}{$\begin{array}{c}\text { Bitki } \\
\text { Boyu } \\
(\mathrm{cm})\end{array}$} & $\begin{array}{c}\text { Koçan } \\
\text { Uzunluğu } \\
(\mathrm{cm})\end{array}$ & $\begin{array}{c}\text { Koçan } \\
\text { Cap1 } \\
(\mathrm{mm})\end{array}$ \\
\hline Ant Cin-98 & $61.625 \mathrm{bc}$ & $64.500 \mathrm{bc}$ & $65.988 \mathrm{bcd}$ & $142.163 \mathrm{cde}$ & $15.675 \mathrm{abc}$ & $28.950 \mathrm{bc}$ \\
\hline Nermin Cin & $62.375 \mathrm{bc}$ & $67.875 \mathrm{ab}$ & $63.350 \mathrm{~cd}$ & $144.875 \mathrm{bcde}$ & $16.600 \mathrm{abc}$ & $29.350 \mathrm{bc}$ \\
\hline S. Kompozit Cin & $61.125 \mathrm{~cd}$ & $65.625 \mathrm{bc}$ & $77.825 \mathrm{~b}$ & $154.250 \mathrm{bc}$ & $17.500 \mathrm{a}$ & $31.275 \mathrm{ab}$ \\
\hline Ç. Sarı Patlak & $66.500 \mathrm{a}$ & $70.125 \mathrm{a}$ & $66.513 \mathrm{bcd}$ & $136.488 \mathrm{de}$ & $12.925 \mathrm{~d}$ & $27.238 \mathrm{c}$ \\
\hline Ç. Kirmız1 Patlak & $58.625 \mathrm{~d}$ & $64.125 \mathrm{c}$ & $67.675 \mathrm{bcd}$ & $136.975 \mathrm{de}$ & $16.038 \mathrm{abc}$ & $31.850 \mathrm{ab}$ \\
\hline Ç. Beyaz Patlak & $62.500 \mathrm{bc}$ & $67.125 \mathrm{abc}$ & $68.275 \mathrm{bcd}$ & $137.650 \mathrm{de}$ & $15.875 \mathrm{abc}$ & $29.550 \mathrm{bc}$ \\
\hline S.Cin & $61.500 \mathrm{bc}$ & $66.125 \mathrm{bc}$ & $69.975 \mathrm{bc}$ & $157.925 \mathrm{~b}$ & $16.388 \mathrm{abc}$ & $31.050 \mathrm{abc}$ \\
\hline S.Beyaz Cin & $64.500 \mathrm{ab}$ & $70.125 \mathrm{a}$ & $106.050 \mathrm{a}$ & $181.525 \mathrm{a}$ & $15.288 \mathrm{bc}$ & $29.425 \mathrm{bc}$ \\
\hline K.Cin & $63.000 \mathrm{bc}$ & $66.625 \mathrm{bc}$ & $67.750 \mathrm{bcd}$ & $154.400 \mathrm{bc}$ & $17.113 \mathrm{ab}$ & $28.213 \mathrm{bc}$ \\
\hline B.Cin & $61.000 \mathrm{~cd}$ & $64.625 \mathrm{bc}$ & $67.975 \mathrm{bcd}$ & $149.500 \mathrm{bcd}$ & $16.988 \mathrm{ab}$ & $29.063 \mathrm{bc}$ \\
\hline B. Beyaz Cin & $63.125 \mathrm{bc}$ & $67.375 \mathrm{abc}$ & $63.425 \mathrm{~cd}$ & $134.375 \mathrm{e}$ & $15.888 \mathrm{abc}$ & $28.600 \mathrm{bc}$ \\
\hline E. Beyaz Cin & $54.750 \mathrm{e}$ & $58.750 \mathrm{~d}$ & $56.338 \mathrm{~d}$ & $134.300 \mathrm{e}$ & $14.825 \mathrm{c}$ & $33.775 \mathrm{a}$ \\
\hline S. Hanköyü & $61.625 \mathrm{bc}$ & $65.875 \mathrm{bc}$ & $70.125 \mathrm{bc}$ & $150.050 \mathrm{bcd}$ & $16.213 \mathrm{abc}$ & $30.075 \mathrm{abc}$ \\
\hline
\end{tabular}

\section{İlk Koçan Yüksekliği (cm)}

İlk koçan yüksekliği bakımından genotipler arasındaki farklılıklar istatistiki olarak önemli olmuştur. En yüksek koçan yüksekliği $106.05 \mathrm{~cm}$ ile Samsun beyaz cin, en düşük ise $56.33 \mathrm{~cm}$ ile Edirne beyaz cin genotiplerinden elde edildiği ve birbirlerinden önemli derecede farklılık oluşturduğu kaydedilmiştir. Ant cin, Çanakkale sarı patlak, Çanakkale kırmızı patlak, Çanakkale Beyaz patlak, Kadirli cin ve Balıkesir cin genotipleri ilk koçan yüksekliği bakımından kendi aralarında istatistiki olarak fark oluşturmayıp aynı grupta ve geçiş grubunda yer almışlardır. Nermin cin ve Balıkesir beyaz cin genotipleri de diğer bir geçiş grubunda yer almıştır. İlk koçan yüksekliğinde Kompozit cin genotipi $77.83 \mathrm{~cm}$ ile ikinci sırayı izlemiştir. İlk koçan yüksekliğinde, Samsun cin ve Sakarya-Hanköyü cin genotipleri kendi aralarında aynı grup ve diğer bir geçiş grubunu oluşturmuşlardır (Çizelge 2).

Tekkanat ve Soylu (2005) 12 cin mısırı genotipiyle yapmış oldukları araştırmada ilk koçan yüksekliğinin 73-109 cm arasında değiştiğini belirtmişlerdir. Bizim araştırmalarımızda ise ilk koçan yüksekliği 56- $106 \mathrm{~cm}$ arasında değiştiği görülmüştür. Peykarestan ve Seify (2012) cin mısırda ekim zamanı ve bitki sıklığının koçan yüksekliğine önemli etkide bulunduğu ve koçan yüksekliğinin 17.87-23.67 cm arasında değiştiğini açıklamışlardır. $\mathrm{Bu}$ bulgular koçan yüksekliğinin genotip ve çevresel faktörlere göre değişkenlik göstereceğini desteklemektedir.

\section{Bitki Boyu (cm)}

Bitki boyu yönünden genotipler arasında istatistiki olarak önemli farklılıklar oluşmuştur. En uzun bitki boyu $181.52 \mathrm{~cm}$ ile Samsun beyaz cin ve onu $157.9 \mathrm{~cm}$ ile ikinci surada Samsun cin genotipi izlediği ve aralarında istatistiki olarak önemli farklılık oluştuğu kaydedilmiştir. En düşük bitki boyu ise Edirne beyaz cin $(134.30 \mathrm{~cm})$ ve Balıkesir beyaz cin $(134.37 \mathrm{~cm})$ genotiplerinden elde edildiği ve diğerlerinden istatistiki olarak farklılık oluşturduğu belirlenmiştir. Kompozit cin ve Kadirli cin genotipi bitki boyu yönünden aynı grupta yer almıştır. Çanakkale sarı patlak, Çanakkale kırmızı patlak ve Çanakkale Beyaz patlak bitki boyu yönünden aralarında istatistiki olarak fark oluşturmadığ 1 ve aynı grupta yer aldığı görülmüştür. Balıkesir cin ve SakaryaHanköyü cin genotipleri aynı grupta yer almış ve bir geçiş grubunu oluşturmuştur. Ant cin ve Nermin cin birbirlerinden farklılık oluşturmayan ayrı geçiş gruplarında yer almıştır (Çizelge 2).

Tekkanat ve Soylu (2005) 12 cin misırı genotipiyle yapmış oldukları araştırmada bitki boyunun 194-240 cm arasında değiştiğini belirtmişlerdir. Öz ve Kapar (2011) 22 adet cin mısırı hibrid genotiple yapmış oldukları çalışmada bitki boyunun 188-245 cm arasında değiştiği ve aralarında önemli farklılıklar oluşturduğunu kaydetmişlerdir. Bizim araştırmalarımızda ise bitki boyunun 134-181 cm arasında değiştiği görülmüştür. Adeleye ve Ayeni (2010) farklı toprak işleme ve bitki sıklığ 1 uygulamasında bitki boylarını 155-174 cm arasında olduğunu kaydetmişlerdir. Daha önceki araştırıcıların bulguları ile bizim bulgularımız arasındaki farklılıklar genotiplerin hibrit ve yerel olmasından kaynaklanmıştır. Ayrıca bu farklılıkların toprak yapısı, sulama, sicaklık ve nem gibi çevresel faktörlerin etkisiyle ortaya çıktığı söylenebilir.

\section{Koçan Uzunluğu (cm)}

Koçan uzunluğu yönünden genotipler arasında istatistiki olarak önemli farklılıklar kaydedilmiştir. En uzun koçan $17.50 \mathrm{~cm}$ ile Kompozit cin genotipinde, en kısa koçan $12.92 \mathrm{~cm}$ ile Çanakkale Sarı patlak genotipinde elde edilmiş ve birbirlerinden önemli derecede farklılık oluşturmuştur. Ant cin ve Nermin cin, 
Çanakkale kırmızı patlak ve Çanakkale Beyaz patlak, Samsun cin, Balıkesir beyaz cin ve Sarkarya-Hanköyü cin koçan boyu yönünden aralarında istatistiki olarak fark oluşturmadığı ve aynı geçiş grupta yer aldığı görülmüştür. Samsun beyaz cin diğer geçiş gruplarından istatistiki olarak fark oluşturmayan diğer bir geçiş grubunu oluşturmuştur. Kadirli cin ve Balıkesir cin genotipi aynı grupta yer alan diğer geçiş grupları ile arasında istatistiki fark oluşturmayan diğer geçiş grubunda yer almıştır. Edirne beyaz cin en kısa koçan uzunluğu $14.82 \mathrm{~cm}$ ile ikinci sırada izlemiştir (Çizelge 2).

Tekkanat ve Soylu (2005) 12 cin mısırı genotipiyle yapmış oldukları araştırmada koçan uzunluğunun 17-20 $\mathrm{cm}$ arasında değiştiğini belirtmişlerdir. Gökmen ve ark.(2001) ekim sıklığının azalmasının koçan boyuna etkili olduğunu ve koçan boyunun 15.7-16.9 arasında değiştiğini belirtmiştir. Bizim araştırmalarımızda ise koçan uzunluğu 12-17 cm arasında değiştiği görülmüştür. Kaya ve ark. (2002) genotiplerin başak uzunluğunun çevreden etkilendiğini belirtmişlerdir.

\section{Koçan Capı (mm)}

Koçanın çapı yönünden genotipler arasında istatistiki olarak önemli farklılıklar kaydedilmiştir. En kalın koçan çapı $33.77 \mathrm{~mm}$ ile Edirne beyaz cin genotipinde kaydedilmiştir. En az kalınlık $27.23 \mathrm{~mm}$ ile Çanakkale sarı patlak genotipinde tespit edilmiştir. Ant Cin 98, Nermin cin, Çanakkale beyaz patlak, Samsun Beyaz cin, Kadirli cin, Balıkesir cin ve Balıkesir beyaz cin kendi aralarında istatistiki olarak fark oluşturmayıp aynı grupta yer almış ve bir geçiş grubunu oluşturmuştur. Kompozit cin ve Çanakkale kırmızı patlak diğer bir geçiş grubunda yer almıştır. Samsun Cin ve Sakarya Hanköyü genotipi aynı grupta olup diğer bir geçiş grubunda yer aldığı kaydedilmiştir (Çizelge 2).

Tekkanat ve Soylu (2005) 12 cin misırı genotipiyle yapmış oldukları araştırmada koçan çapı 33-40 mm arasında değiştiğini belirtmişlerdir. Peykarestan ve Seify (2012) cin mısırda ekim zamanı ve bitki sıklığının koçan çapına önemli etkide bulunduğu ve koçan çapının 40.2-50.2 mm arasında değiştiğini açıklamışlardır. Bizim araştırmalarımızda ise koçan çapı 27-33 mm arasında değiştiği görülmüştür. Mani ve Dadari (2003) verime en büyük katkı yapan özeliklerden birinin koçan çapı olduğunu açıklamıştır.

\section{Koçanda Sıra Sayısı (adet)}

Koçanda sıra sayısı yönünden genotipler arasında istatistiki olarak önemli farklılıklar kaydedilmiştir. Ant Cin 98, Nermin cin, Çanakkale kırmızı patlak, Çanakkale beyaz patlak, Samsun Cin, Samsun Beyaz cin, Balıkesir cin ve Sakarya Hanköyü genotipleri koçanda sıra sayısı yönünden kendi aralarında istatistiki farklılık oluşturmayıp, aynı grupta yer almışlardır. En az koçanda sıra sayısı Balıkesir beyaz cin genotipinden elde edilmiş ve diğer genotiplerden önemli farklılık oluşturduğu kaydedilmiştir. Kompozit cin, Kadirli cin ve Edirne beyaz cin kendi aralarında farklılık oluşturmayıp bir geçiş grubunu oluşturmuştur. Çanakkale Sarı patlak koçanda sıra sayısı yönünden diğerlerinden farklı bir grupta yer almıştır (Çizelge 3).

Todorovic ve ark. (2012) kendilenmiş misır hatlarında koçanda sıra sayısının 11-17, hibridlerde ise 13-15 adet arasında değiştiğini belirtmişlerdir. Araştırmacıların bu bulguları ile çalışmamızdaki koçanda sıra sayısının 12-16 adet arasında değiştiği bulgusu paralellik göstermektedir.

Çizelge 3. Yerel cin mısırı genotiplerinin bazı verim ve kalite özelliklerinden elde edilen iki yıllık ortalama değerleri

\begin{tabular}{|l|c|c|c|c|c|c|c|}
\hline \multicolumn{1}{|c|}{ Genotip } & $\begin{array}{c}\text { Koçanda sıra } \\
\text { sayıs1 } \\
\text { (adet) }\end{array}$ & $\begin{array}{c}\text { Koçan sirasında } \\
\text { tane sayıs1 } \\
\text { (adet) }\end{array}$ & $\begin{array}{c}\text { Bitkide } \\
\text { koçan sayıs1 } \\
(\text { adet })\end{array}$ & $\begin{array}{c}\text { Tane } \\
\text { oran1 } \\
(\%)\end{array}$ & $\begin{array}{c}\text { Tane } \\
\text { verimi } \\
\left(\mathrm{kg} \mathrm{da}^{-1}\right)\end{array}$ & $\begin{array}{c}\text { Patlama } \\
\text { hacmi } \\
\left(\mathrm{m}^{3} \mathrm{~g}^{-1}\right)\end{array}$ & $\begin{array}{c}\text { Patlamamış tane } \\
\text { oranı } \\
(\%)\end{array}$ \\
\hline Ant Cin-98 & $15.375 \mathrm{a}$ & $36.175 \mathrm{abc}$ & 1.111 & $80.393 \mathrm{a}$ & $446.13 \mathrm{~b}$ & $19.975 \mathrm{bc}$ & $12.863 \mathrm{~d}$ \\
\hline Nermin Cin & $15.350 \mathrm{a}$ & $38.850 \mathrm{ab}$ & 1.219 & $77.186 \mathrm{ab}$ & $443.13 \mathrm{~b}$ & $22.575 \mathrm{a}$ & $12.288 \mathrm{~d}$ \\
\hline S. Kompozit Cin & $14.850 \mathrm{ab}$ & $39.525 \mathrm{a}$ & 1.063 & $79.569 \mathrm{a}$ & $458.00 \mathrm{ab}$ & $20.550 \mathrm{abc}$ & $8.938 \mathrm{~d}$ \\
\hline Ç. Sarı Patlak & $14.025 \mathrm{~b}$ & $29.325 \mathrm{~d}$ & 1.159 & $79.866 \mathrm{a}$ & $287.38 \mathrm{~d}$ & $13.800 \mathrm{f}$ & $24.363 \mathrm{a}$ \\
\hline Ç. Kırmızı Patlak & $15.700 \mathrm{a}$ & $40.866 \mathrm{a}$ & 1.085 & $81.392 \mathrm{a}$ & $437.75 \mathrm{~b}$ & $17.300 \mathrm{de}$ & $8.763 \mathrm{~d}$ \\
\hline Ç. Beyaz Patlak & $15.625 \mathrm{a}$ & $38.575 \mathrm{ab}$ & 1.225 & $78.923 \mathrm{a}$ & $369.50 \mathrm{c}$ & $18.463 \mathrm{~cd}$ & $11.400 \mathrm{~d}$ \\
\hline S.Cin & $15.300 \mathrm{a}$ & $35.875 \mathrm{abc}$ & 1.148 & $81.035 \mathrm{a}$ & $461.13 \mathrm{ab}$ & $18.663 \mathrm{bcd}$ & $11.113 \mathrm{~d}$ \\
\hline S.Beyaz Cin & $15.900 \mathrm{a}$ & $31.375 \mathrm{~cd}$ & 1.128 & $72.329 \mathrm{~b}$ & $377.38 \mathrm{c}$ & $14.938 \mathrm{f}$ & $11.825 \mathrm{~d}$ \\
\hline K.Cin & $15.225 \mathrm{ab}$ & $36.575 \mathrm{abc}$ & 1.151 & $80.851 \mathrm{a}$ & $480.25 \mathrm{ab}$ & $21.025 \mathrm{ab}$ & $13.063 \mathrm{~cd}$ \\
\hline B.Cin & $15.750 \mathrm{a}$ & $40.166 \mathrm{a}$ & 1.095 & $77.666 \mathrm{ab}$ & $498.50 \mathrm{a}$ & $19.263 \mathrm{bcd}$ & $13.200 \mathrm{~cd}$ \\
\hline B. Beyaz Cin & $12.750 \mathrm{c}$ & $35.200 \mathrm{abc}$ & 1.255 & $79.180 \mathrm{a}$ & $379.38 \mathrm{c}$ & $15.550 \mathrm{ef}$ & $18.112 \mathrm{bc}$ \\
\hline E. Beyaz Cin & $14.850 \mathrm{ab}$ & $33.275 \mathrm{bcd}$ & 1.165 & $83.008 \mathrm{a}$ & $456.63 \mathrm{ab}$ & $10.750 \mathrm{~g}$ & $21.775 \mathrm{ab}$ \\
\hline S. Hanköyü & $15.950 \mathrm{a}$ & $39.900 \mathrm{a}$ & 1.284 & $81.251 \mathrm{a}$ & $480.00 \mathrm{ab}$ & $18.600 \mathrm{~cd}$ & $11.725 \mathrm{~d}$ \\
\hline
\end{tabular}

Koçan Sırasında Tane Sayısı (adet)

Koçan sırasında tane sayısı yönünden genotipler arasında istatistiki olarak önemli farklılıklar kaydedilmiştir. En fazla boyuna tane 40.86 adet ile
Çanakkale kırmızı patlak genotipinde elde edilirken onu sırayla Balıkesir cin, Sakarya Hanköyü cin ve Kompozit cin genotipinin izlediği ve aynı grupta yer aldığı tespit edilmiştir. Çanakkale sarı patlak genotipi 29.32 adet 
tane ile en az koçan sırasında tane sayısına sahip olmuştur. Nermin cin ve Çanakkale beyaz patlak koçan sırasında tane sayısı yönünden aynı grupta yer almış ve bir geçiş grubunda yer almıştır. Ant Cin 98, Samsun Cin, Kadirli cin, Balıkesir beyaz cin aynı grup içinde yer almış, diğer geçiş grubundan istatistiki olarak farklılık oluşturmayan diğer bir geçiş grubunu oluşturmuştur. Edirne beyaz cin ve Samsun Beyaz cin birbirlerinden farklı geçiş grubunda olmasına rağmen, koçan sırasında tane sayısı yönünden istatistik olarak birbirlerinden farklı olmayan başka bir geçiş gruplarında yer almıştır (Çizelge 3 ).

Cengiz (2006) $28 \quad \mathrm{~F}_{1}$ kombinasyonu ve 8 kendilenmiş hatla yapmış olduğu araştırmada mısırın koçan sırasında tane sayısının 22.7 - 51.0 adet arasında değiştiğini; bu durumun koçan sırasında tane sayının değişken olduğunu vurgulamaktadır. Bu sonuçlar bizim çalışmamızla uyumlu olup, koçan sırasında tane sayısının genotip, iklim, toprak ve çevresel koşullardan etkilendiğini ortaya koymaktadır.

\section{Bitkide Koçan Sayısı (adet)}

Bitkide koçan sayısı yönünden genotiplerin arasında istatistiki olarak farklılıklar olmadığı tespit edilmiştir (Çizelge 3). Bitki başına koçan sayısı en az 1.063 adetle Sakarya kompozit cin genotipinde elde edilmiştir. En yüksek bitki başına koçan sayısı 1.284 adetle Sakarya Hanköyü popülasyununda kaydedilmiştir. Değer genotiplerde ise bitki başına koçan sayısı bu iki değer arasında değişim göstermiştir.

Grosbach (2008) cin misırda uyguladıkları siklık denemesinde bitkide koçan sayısı yönünden bitki sıra üzeri mesafesinin etkili olmadığını bildirmişlerdir. Adeleye ve Ayeni (2010) farklı toprak işleme ve bitki sıklığ 1 uygulamasında bitkide koçan sayısının 1.18-1.63 adet arasında değişim gösterdiğini belirtmişlerdir. Bulut ve ark. (2008) silajlık mısırda bitkide koçan sayısını 1.2 - 1.5 adet bitki olarak kaydetmişlerdir.

\section{Koçanda Tane Oranı (\%)}

Koçanda tane oranı yönünden genotipler arasında istatistiki olarak önemli farklılıklar vardır. En yüksek koçan tane oranı \% 83.00 olarak Edirne Beyaz Cin genotipinde gerçekleşmiş, diğer Ant Cin 98, Kompozit cin, Çanakkale sarı patlak, Çanakkale kırmızı patlak, Çanakkale beyaz patlak, Samsun Cin, Kadirli cin, Balıkesir beyaz cin, Edirne beyaz cin ve Sakarya Hanköyü genotipleri ile aynı grupta yer almış ve aralarında istatistiki olarak önemli farklılık olmadığ kaydedilmiştir. En düşük koçanda tane oranı \% 72.32 ile Samsun Beyaz cin genotipinde tespit edilmiştir. Nermin cin ve Balıkesir cin genotipleri aynı grupta yer almış bir geçiş grubunu oluşturmuştur (Çizelge 3).

Gökmen ve ark. (2001) koçan tane ağırlığına bitki sıklığı ve azot dozunun olumlu etkide bulunduğunu kaydetmişlerdir. Adeleye ve Ayeni (2010) farklı toprak işleme ve bitki sıklığı uygulamasının koçan tene ağırlığına etkili olduğunu tespit etmişlerdir. Mani ve
Dadari (2003) verime en büyük katkıda bulanan özelliklerden biri koçanın tane ağırlığı olduğunu belirtmişlerdir. Severini ve ark (2011) çiçeklenme döneminde koçanda biriken karbonhidratın tane verimi, tane sayısına ve koçanın tane ağırlığına önemli etkisi olduğunu belirtmişlerdir. Ayrıca, araştırmacılar çiçeklenme döneminde bitki gelişiminin azaltıcı uygulamaların koçan tane ağırlığı üzerine etkisi atdişi misira göre cin misirda daha az olduğunu kaydetmişlerdir.

\section{Tane Verim $\left(\mathrm{kg} \mathrm{da}^{-1}\right)$}

Dekara verim yönünden genotipler arasındaki istatistiki olarak önemli farklılıklar kaydedilmiştir. Balıkesir cin genotipi $498.50 \mathrm{~kg} \mathrm{da}^{-1}$ ile en yüksek tane verimi sahip olmuştur. En yüksek tane veriminin sırasıyla Kadirli cin $\left(480.25 \mathrm{~kg} \mathrm{da}^{-1}\right)$, Sakarya Hanköyü (480.00 kg da ${ }^{-1}$ ), Samsun cin (461.13 $\mathrm{kg} \mathrm{da}^{-1}$ ), Kompozit cin $\left(458.00 \mathrm{~kg} \mathrm{da}^{-1}\right)$ ve Edirne beyaz cin (456.63 $\mathrm{kg} \mathrm{da}^{-1}$ ) genotipleri izlemiş ve aynı geçiş grubunda yer almıştır. Ant cin 98, Nermin cin ve Çanakkale kırmızı patlak genotipinde sırasıyla 446.13, 443.13 ve $437.75 \mathrm{~kg} \mathrm{da}^{-1}$ tane verimi alınmıș ve kendi aralarında istatistiki olarak fark kaydedilmemiş ve diğerlerinden istatistiki olarak önemli farklılık kaydedilmiştir. En az tane verimi $287.38 \mathrm{~kg} \mathrm{da}^{-1}$ ile Çanakkale sarı patlak genotipinde gerçekleşmiş ve diğerlerinden farklı bulunmuştur. En düşük verimi sırasıyla $369.50,377.38$ ve $379.38 \mathrm{~kg} \mathrm{da}^{-1}$ ile Çanakkale beyaz patlak, Samsun beyaz cin ve Balıkesir beyaz cin genotipleri izlediği ve kendi aralarında istatistiki olarak fark olmadığı kaydedilmiştir (Çizelge 3).

Tane verimini Tekkanat ve Soylu (2005) 499-735 kg/da, Grosbach (2008) 721-753 kg da ${ }^{-1}$, Öz ve Kapar (2011) 353-539 $\mathrm{kg} \mathrm{da}^{-1}$ arasında değiştiğini ve genotipler aralarında önemli farklılıklar oluşturduğunu belirtmişlerdir. Gökmen ve ark. (2001) tane veriminin $385-497 \mathrm{~kg} \mathrm{da}^{-1}$ arasında değiştiğini ve azot dozlarının tane verimini artırdığını, Mitrovic (2012), Tsimba ve ark. (2013a) çevresel farklılıkların verimi etkileyeceğini açıklamıştır. İlker ve ark. (2009) genotiplerin çevrelerden etkilendikleri ve bazı gonotiplerin çevreye uyumun yüksek olması nedeniyle daha yüksek verim elde edildiğini açıklamışlardır. Rattalino Edreira ve Otegui (2012) sıcaklık gibi çevresel faktörlerin verimi etkilediğini genotipler arasında varyasyon oluşturduğunu belirtmiştir. Otinga ve ark. (2013) misıra verilen fosfor gübresine göre, çiftlik gübresi uygulanmasının özellikle fakir topraklarda (\% 25-50) mısırın tane verimini önemli derecede arttırdığını belirtmişlerdir. Adeleye ve Ayeni (2010) cin misırda farklı toprak işleme ve bitki sıklığı uygulamasında tane veriminin etkilendiğini ve verimin 263-638 $\mathrm{kg} \mathrm{da}^{-1}$ arasında değişim gösterdiğini belirtmişlerdir. Peykarestan ve Seify (2012) cin misırında ekim zamanı ve bitki sıklığının tane verimine önemli etkide bulunduğunu ve tane veriminin $525-778 \mathrm{~kg} \mathrm{da}^{-1}$ arasında değiştiğini açıklamışlardır. Videnovic ve ark. 
(2013) misırda tane veriminin yıllara göre farklılık gösterdiğini belirtmiştir. Bu araştırmalardan elde edilen bulgulara ek olarak, araştırmamızdan elde edilen sonuçlar, verimin uygulama faktörleri kadar genotip farklılıklardan da etkilenebileceğini göstermiştir.

\section{Patlama Hacmi $\left(\mathrm{m}^{3} \mathrm{~g}^{-1}\right)$}

Patlama hacmi yönünden genotipler arasında önemli farklılıklar kaydedilmiştir. En yüksek patlama hacmi $22.57 \mathrm{ml}$ ile Nermin cin genotipinde kaydedilmiştir. En yüksek patlama hacmini sırasıyla $21.02,20.55,19.97$, 19.26, 18.66, 18.60, 18.46, 17.30 ve $15.55 \mathrm{~m}^{3} \mathrm{~g}^{-1}$ ile Kadirli cin, Kompozit cin, Ant Cin 98, Balıkesir cin, Samsun Cin, Sakarya Hanköyü, Çanakkale beyaz patlak, Çanakkale kırmızı patlak ve Balıkesir beyaz cin genotipleri farklı geçiş grupları oluşturarak izlemiştir. En düşük patlama hacmi $10.75 \mathrm{~m}^{3} \mathrm{~g}^{-1}$ ile Edirne beyaz cin genotipinde elde edilmiștir. Çanakkale sarı patlak ve Samsun Beyaz cin genotipleri sirasiyla 13.8 ve $14.98 \mathrm{~m}^{3}$ $\mathrm{g}^{-1}$ patlama hacmi ile ayrı grupta yer alarak diğerlerinden istatistiki olarak önemli farklılık oluşturmuştur (Çizelge 3.).

Öz ve Kapar (2011) 22 adet hibrid genotiple yapmıs oldukları çalışmada patlama hacminin $38-48 \mathrm{~m}^{3} \mathrm{~g}^{-1}$ arasında değiştiği ve aralarında önemli farklılıklar oluşturduğunu kaydetmişlerdir. Bizim sonuçlarda daha düşük değerler elde edilmiştir. Ertaş ve ark (2008) cin misırının \% 12 nemde patlama özelliğinin geliştiğini ve patlama hacmine tane genişliği, küreselliği ve renk değerlerinin etkili olduğunu belirtmişlerdir. AllredCoyle et al., (2000) tohum patlama hacminin tohum ağırlığına bağlı olduğunu tespit etmişlerdir. Bizim sonuçlarda patlama hacminin düşük olmasını, yerel çeşit olmas1 ve \% 14-15 nemde patlama hacmine bakılmasından kaynaklanmış olarak açıklayabiliriz.

\section{Patlamamış Tane Oranı (\%)}

Patlamamıș tane yönünden genotipler arasında önemli farklılıklar oluşmuştur. En fazla patlamamış tane oranı \% 24.36 oranla Çanakkale Sarı patlak mısırda kaydedilmiştir. En az patlamamış tane oranı \% 8.93 oranla Kompozit cin genotipinden elde edildiği, onu sirayla \% 8.76, 11.11, 11.40, 11.72, 11.82, 12.28 ve 12.86 oran ile Çanakkale kırmızı patlak, Samsun Cin, Çanakkale beyaz patlak, Sakarya Hanköyü, Samsun Beyaz cin, Nermin cin ve Ant Cin 98 genotiplerinin izlediği, istatistiki olarak aralarında fark oluşturmadığı, aynı grupta yer aldığı kaydedilmiştir. Edirne beyaz cin genotipi \% 21.72 ile ikinci sirada en fazla patlamayan tane oranına sahip olmuş ve bir geçiş grubunda yer almıştır. Kadirli cin ve Balıkesir cin genotipleri patlamayan tane oranı yönünde aralarında istatistiki olarak fark oluşturmayıp aynı grupta diğer bir geçiş grubuna sahip olmuşlardır. Patlamayan tane oranı yönünden Balıkesir beyaz cin genotipi, diğer iki geçiş grubu arasında bir geçiş grubunda yer almıştır (Çizelge 3).
Öz ve Kapar (2011) patlamamış tane oranının \% 2.8.1-10.1 arasında değiştiği ve aralarında önemli farklılıklar oluşturduğunu kaydetmişlerdir. Araştırmada kullanılan genotipler yerel genotipler olduğundan yüksek oranda patlamayan genotipler tespit edilmiştir. Ertaş ve ark (2008) cin mısırının patlamamış tane oranını \% 12-16 arasında bulduklarını ve patlamama oranına tanenin nem içeriğinin etkili olduğunu açıklamışlardır. Bizim çalışmamızda kullanılan iki çeşit (Nermin cin ve Ant Cin-98) Ertaş ve ark (2008) denemesinde kullanılan çeşitlerden olup, benzer sonuçlar elde edilmiştir.

\section{KAYNAKLAR}

Adeleye, E.O., Ayeni, L.S. 2010. Effects of Soil Preparation Methods and Spacing on the Growth and Yield of Popcorn on an Alfisol in Southwestern Nigeria. Department of Agricultural Science Education, Adeyemi College of Education, Ondo, Nigeria. Researcher 2(10): 1-6.

Allred Coyle, T.A., Toma, R.B., Reiboldt, W., Thakur, M. 2000. Effects of Moisture Content, Hybrid Variety, Kernel Size, and Microwave Wattage on The Expansion Volume of Microwave Popcorn. Int. J. Food Sci. Nutr. 51: 389-394.

Allard, R.W., Bradshaw, A.D. 1964. Implications of Genotype-Environmental Interactions in Applied Plant Breeding. Crop Science, 4: 503-508.

Anonim, 2014. Kahramanmaraş Meteoroloji İl Müdürlüğü Kayıtları. Kahramanmaraş.

Anonim. 2015. Bitkisel Üretim Verileri. http:// www.tuik.gov.tr, (Erişim tarihi: 02 Nisan 2015).

Bulut, S., Çağlar, Ö., Öztürk, A. 2008. Bazı Mısır Çeşitlerinin Erzurum Ovası Koşullarında Silaj Amaçlı Yetiştirilme Olanakları. Atatürk Üniv. Ziraat Fak. Dergisi, 39 (1): 83-91.

Cengiz, R. 2006. Misır Hatları Arasındaki 8x8 Yarım Diallel Melez Döllerinde Verim ve Verim Unsurlarının Kalıtımları Üzerine Araştırmalar. Trakya Üniversitesi, Fen Bilimleri Enstitüsü. Tarla Bitkileri ABD, Yüksek Lisans Tezi. 160s.

Cesurer, L. 1995. Kahramanmaraş Koşullarında Ekim Zamanı ve Ekim Sıklığının Şeker Mısırında Taze Koçan Verimine ve Diğer Bazı Tarımsal ve Bitkisel Özelliklere Etkisi. Ç.Ü. Fen Bilimleri Enstitüsü, Tarla Bitkileri ABD, Doktora Tezi, 205p, Adana.

Ertaş, N., Soylu, S., Bilgiçli, N. 2008 Misırın Fiziksel Özellikleri ile Patlama Kalitesi Arasındaki İlişkilerin Belirlenmesi Üzerine Bir Araştırma. Türkiye 10. G1da Kongresi, 21-23 May1s, Erzurum, 467-470.

Gökmen, S. Sencar, Ö., Sakin, M.A. 2001. Response of Popcorn (Zea mays everta) to Nitrogen Rates and Plant Densities. Turk. J. Agric. For., 25: 15-23.

Grosbach, J. 2008. The Effect of Row Spacing on the Yield and Plant Growth of Popcorn (Zea mays). McPherson College Division of Science and Technology. Cantaurus, Vol. 16, 9-12. 
İdikut, L., Kara. S.N. 2001. The Effects of Previous Plants and Nitrogen Rates on Second Crop Corn. Turkish Journal of Field Crops, 16(2): 239-244.

İlker, E., Aykut Tonk, F., Çaylak, Ö., Tosun, M., Özmen, İ. 2009. Assessment of Genotype X Environment Interactions for Grain Yield in Maize Hybrids Using AMMI and GGE Biplot Analyses. Turkish J. of Field Crops, 14(2): 123 - 135.

Kaya, Y., Palta, C., Taner, S. 2002. Additive Main Effects and Multiplicative Interactions Analysis of Yield Performance in Bread Wheat Genotypes a Cross Environments. Turkish Journal Agriculture Forestry, 26: 275-279.

Mani, H., Dadari, A. 2003. Growth And Yield Analysis of Irrigated Popcorn (Zea Mays Evarta) Grown in Kadawa as Affected By Sowing Date and Intra-Row Spacing. Using Correlation Co-Efficient. Asset Series A, 3 (4):63-70.

Mitrovic, B., Stanisavljevi, D. Treski S., Stojakovic, M., İvanovic, M., Bekavac, G., Rajkovic, M. 2012. Evaluation of Experimental Maize Hybrids Tested in Multi-Location Trials Using Ammi and Gge Biplot Analyses. Turkish Journal of Field Crops, 17(1): 35 40.

Otinga, A.N., Pypers, P., Okalebo, J.R., Njoroge, R., Emong'ole, M., Six, L., Vanlauwe, B., Merckx, R. 2013. Partial Substitution of Phosphorus Fertiliser by Farmyard Manure and Its Localised Application Increases Agronomic Efficiency and Profitability of Maize Production. Field Crops Research, 140: 32 43.

Öz, A., Kapar, H. 2011. Determination of Grain Yield, Some Yield and Quality Traits of Promising Hybrid Popcorn Genotypes. Turkish Journal of Field Crops, 16(2): 233-238

Özkan, A., Ülger, A.C. 2011. Çukurova Ekolojik Koşullarında Değişik Azot Dozu Uygulamalarının İki Cin Mısırı (Zea mays L. everta Sturt.) Çeşidinde Tane Verimi ve Bazı Tarımsal Özelliklere Etkisi. YYÜ. Tar. Bil. Dergisi, 21(3):198-208.

Peykarestan, B., Seify, M. 2012. Impact of Sowing Date on Growth and Yield Attributes of Pop Corn Grown
Under Different Densities. International Research Journal of Applied and Basic Sciences, 3 (1): 85-91.

Rattalino Edreira, J.I., Otegui M.E. 2012. Heat stress in temperate and tropical maize hybrids: Differences in Crop Growth, Biomass Partitioning and Reserves Use. Field Crops Research, 130: 87-98.

Saltık, A. 2010. Genetiği değiştirilmiş gıdalar ve halk sağlığı. Farklı Boyutları ile genetiği değiştirilmiş organizmalar. 33-40. Ankara Tabip Odas1.

Severinia, A. D., Borrasb, L. Westgatec, M. E. Cirilo, A. G. 2011. Kernel Number and Kernel Weight Determination in Dent and Popcorn Maize. Field Crops Research, 120: 360-369

Tekkanat, A. Soylu, S. 2005. Cin Mısırı Çeşitlerinin Önemli Tarımsal Özelliklerinin Belirlenmesi. S.Ü. Ziraat Fakültesi Dergisi, 19 (37): 41-50.

Todorovic, G., Secanski M.,, Zivanovic, T., Protic, R., Kostic,.M., Jovanovic, S., Bozovic, D. 2012. Inbred Lines of Different Cycles of Selection - Donors of Favourable Alleles for The Improvement of The Kernel Row Number of F1 Maize Hybrids. Turkish Journal of Field Crops, 17(2):198-202.

Tsimba, R., Edmeades, G.O., Millner, J.P., Kemp, P.D. 2013a. The Effect of Planting Date on Maize: Grain Yields and Yield Components. Field Crops Research, 150: 135-144.

Tsimba, R., Edmeades, G.O., Millner, J.P., Kemp, P.D. 2013b. The Effect of Planting Date on Maize: Phenology, Thermal Timedurations and Growth Rates in a Cool Temperate Climate. Field Crops Research, 150: 145-154.

Ülger, A.C., İbrikçi, H., Cakır, B., Güzel, N. 1997. Influence of Nitrogen Rates and Row Spacing on Corn Yield, Protein Content and Other Plant Parameters. J. of Plant Nutrition, 20:1697-1709.

Videnovic, Z., Jovanovic Z., Duvanovic, Z., Simic, M., Srdic, J., Dragicevic, V., Spasojevic, I. 2013. Effect Of Long Term Crop Rotation and Fertiliser Application on Maize Productivity. Turkish Journal of Field Crops, 18(2), 233-237. 